\title{
Dipeptidyl Peptidase-4 Inhibitor (Vildagliptin) Improves Glycemic Control After Meal Tolerance Test by Suppressing Glucagon Release
}

\author{
Aki Okamoto $\cdot$ Hirohide Yokokawa • \\ Hironobu Sanada
}

Published online: 10 September 2014

(C) The Author(s) 2014. This article is published with open access at Springerlink.com

\begin{abstract}
Aim We aimed to evaluate changes in insulin and glucagon secretion, as well as glucose levels, with a meal tolerance test (MTT) before and after 6 months of treatment with vildagliptin in a clinical setting.

Materials and Methods Participants were 15 patients with uncontrolled type 2 diabetes mellitus (glycated hemoglobin $\left[\mathrm{HbA}_{1 \mathrm{c}}\right]$ over $6.9 \%$ for more than 3 months). MTTs were conducted before and 6 months after addition of vildagliptin (50 mg twice daily [bid]). Blood samples were collected immediately before, and 1 and $2 \mathrm{~h}$ after the test meal for measurement of blood glucose concentration, immunereactive insulin (IRI), and glucagon. $\mathrm{HbA}_{1 \mathrm{c}}$ was measured at 6 months.

Results Mean age of participants was $55.5 \pm 2.8$ years, and ten $(66.7 \%)$ were male. Mean $\mathrm{HbA}_{1 \mathrm{c}}$ significantly improved from 7.6 to $6.8 \%$ at 6 months after addition of vildagliptin. Blood glucose at 1 and $2 \mathrm{~h}$ after the test meal was significantly reduced after addition of vildagliptin, while the reduction in glucagon showed borderline significance and IRI showed no difference. In a comparison of
\end{abstract}

\section{A. Okamoto \\ OKM Okamoto Medical Clinic, Tokyo, Japan}

H. Yokokawa ( $\square)$

Department of General Medicine, Juntendo University School of Medicine, Hongo 2-1-1, Bunkyo-ku, Tokyo 113-8421, Japan e-mail: yokokawa@pa3.so-net.ne.jp

H. Sanada

Division of Health Science Research, Fukushima Welfare Federation of Agricultural Cooperatives, Fukushima, Japan

H. Sanada

Department of Tumor and Host Bioscience, Fukushima Medical University School of Medicine, Fukushima, Japan blood glucose-related parameters between subgroups based on median glucose change in area under the curve during MTT $\left(\triangle \mathrm{AUC}_{0-2 \mathrm{~h}}\right)$, glucagon $\triangle \mathrm{AUC}_{0-2 \mathrm{~h}}$ was significantly lower in the group with more improved glucose levels $\left(\triangle \mathrm{AUC}_{0-2 \mathrm{~h}} \geq 65 \mathrm{mg} / \mathrm{dL}\right.$ ), but that of IRI did not differ. Conclusion Suppression of glucagon release by vildagliptin may improve glycemic control without increasing insulin levels in patients with type 2 diabetes.

\section{Introduction}

Hyperglycemia in patients with type 2 diabetes mellitus (T2DM) occurs due to a lack of insulin release and/or an increase in insulin resistance. In Japan, sulfonylureas have been widely prescribed as first-choice drugs to treat T2DM because they enhance insulin secretion. However, the pathophysiology of T2DM is due to both a relative decrease in insulin activity and a paradoxical elevation of glucagon, as reflected in the increase of glucagon after a glucose or meal tolerance test (MTT) [1]. Mechanisms underlying the paradoxical glucagon elevation are not clear, but the lack of insulin release is considered a possible mechanism since insulin suppresses glucagon release [2].

Incretins are endogenous gut-derived peptide hormones that enhance insulin secretion and suppress glucagon release in a glucose-dependent manner [3]. Dipeptidyl peptidase (DPP)-4 inhibitors improve glycemic control in patients with T2DM by suppressing rapid cleavage of incretins, resulting in increased incretin concentration in the blood [4]. Based on this pharmacological background, DPP-4 inhibitors are currently prescribed for treating patients with T2DM. Although many studies have reported the glycated hemoglobin $\left(\mathrm{HbA}_{1 \mathrm{c}}\right)$-lowering effects and safety of DPP-4 inhibitors, the extent to which enhancing 
insulin secretion and suppressing glucagon release contribute to glycemic control during treatment with DPP-4 inhibitors in actual clinical settings is unclear.

In this study, we evaluated changes in glucose, insulin, and glucagon after an MTT.

\section{Materials and Methods}

\subsection{Study Participants}

Participants were patients with T2DM at one medical clinic specific for diabetes treatment in Tokyo, Japan, who had $\mathrm{HbA}_{1 \mathrm{c}}$ measurements over $6.9 \%$ (National Glycohemoglobin Standardization Program [NGSP]) for more than 3 months, and were being treated with diet and exercise therapy and/or being treated with oral antidiabetic agents (OADs) other than vildagliptin (Equa ${ }^{\circledR}$, Novartis Pharma K.K., Tokyo, Japan). Patients who met the following exclusion criteria were excluded from the study: type 1 diabetes mellitus, severe cardiovascular diseases, end-stage renal disease, severe liver damage, dementia. Further aggressive therapy (addition of vildagliptin $50 \mathrm{mg}$ twice daily [bid]) to manage glycemic controls was provided to the eligible patients. Informed consent was obtained from all patients.

\subsection{Study Design}

The present study was carried out from April 2011 to April 2013. Patients were fasted beginning at 9 p.m. the day before the MTT and received a test meal for breakfast. The test meal was specially cooked according to Japanese Diabetes Society recommendations. We asked a meal delivery company (Seven-Eleven Japan Co., Ltd.) to cook the special test meal with consideration of the following components (total calories $491.5 \mathrm{kcal}$; carbohydrate $75 \mathrm{~g}$; fat $11.5 \mathrm{~g}$; protein $11.5 \mathrm{~g}$ ). The MTT was administered at 8 a.m., and patients ate the test meal within $15 \mathrm{~min}$. Blood samples were collected immediately before and 1 and $2 \mathrm{~h}$ after finishing the test meal for simultaneous measurement of blood glucose, immune-reactive insulin (IRI), and glucagon concentrations. Plasma glucose levels were measured with the glucose dehydrogenase method. IRI was measured with enzyme immunoassay. Plasma glucagon concentrations were measured with radioimmunoassay. The MTT was conducted before and 6 months after the addition of vildagliptin.

\subsection{Statistical Analysis}

Variables are presented as mean \pm standard error (SE) for continuous variables and number and percentage (\%) for categorical variables. Homeostasis model assessmentinsulin resistance (HOMA-IR) and Homeostasis model assessment-beta cell function (HOMA- $\beta$ ) were calculated using the following equation: HOMA-IR $=$ (fasting IRI $[\mu \mathrm{U} / \mathrm{mL}] \times$ fasting blood glucose concentration $[\mathrm{mg} / \mathrm{dL}]) /$ 405 ; HOMA- $\beta=(360 \times$ fasting IRI $[\mu \mathrm{U} / \mathrm{mL}]) /($ fasting blood glucose concentration $[\mathrm{mg} / \mathrm{dL}])-63$ [5].

The area under the curve $\left(\mathrm{AUC}_{0-2 \mathrm{~h}}\right)$ during MTT was calculated to evaluate changes in three parameters (glucose, IRI, and glucagon concentrations). We classified the patients into subgroups based on median glucose $\Delta \mathrm{AUC}_{0-2 \mathrm{~h}}$ to evaluate the characteristics considering improvement of blood glucose concentrations after addition of vildagliptin, which was calculated as the difference between glucose $\mathrm{AUC}_{0-2 \mathrm{~h}}$ after and before adding vildagliptin. For paired analysis, the Wilcoxon signed-rank test was used for continuous variables. $P<0.05$ was considered statistically significant. All statistical analyses were performed using the Statistical Package for JMP 10 (SAS Institute Inc., Cary, NC, USA).

\section{Results}

Table 1 shows the baseline characteristics of the 15 patients (before adding vildagliptin). Mean age was $55.5 \pm 2.8$ years, and ten $(66.7 \%)$ were male. Mean $\mathrm{HbA}_{1 \mathrm{c}}$ at baseline was $7.6 \pm 0.1 \%$. Four patients $(26.7 \%)$ were being treated with glimepiride and seven $(46.7 \%)$ with metformin. Mean $\mathrm{HbA}_{1 \mathrm{c}}$ on the day of the MTT 6 months after addition of vildagliptin was $6.8 \pm 0.1 \%$, which was significantly lower than at baseline $(P<0.01)$. Mean body weight slightly decreased by $0.27 \pm 0.59 \mathrm{~kg}$ after treatment with vildagliptin, which was not a significant change $(P=0.65)$.

Table 1 Patient baseline characteristics before the addition of vildagliptin $(N=15)$

\begin{tabular}{ll}
\hline Variables & $N(\%)$ or mean $\pm \mathrm{SE}$ \\
\hline Male & $10(66.7)$ \\
Age (years) & $55.5 \pm 2.8$ \\
Body weight $(\mathrm{kg})$ & $75.5 \pm 2.9$ \\
BMI $\left(\mathrm{kg} / \mathrm{m}^{2}\right)$ & $26.9 \pm 0.8$ \\
Agents & \\
$\quad$ Glimepiride & $4(26.7)$ \\
$\quad$ Metformin & $7(46.7)$ \\
HbA $_{1 \mathrm{c}}(\%)$ & $7.6 \pm 0.1$ \\
Fasting glucose $(\mathrm{mmol} / \mathrm{L})$ & $7.73 \pm 0.39$ \\
Fasting IRI $(\mu \mathrm{U} / \mathrm{L})$ & $7.17 \pm 0.97$ \\
\hline
\end{tabular}

$B M I$ body mass index, $H b A_{I c}$ glycated hemoglobin $\mathrm{A}_{1 \mathrm{c}}, I R I$ immunereactive insulin, $S E$ standard error 
Figure 1 shows changes in blood glucose, IRI, and glucagon after the meal test before and 6 months after adding vildagliptin. Blood glucose at 1 and $2 \mathrm{~h}$ after the test meal were significantly reduced with vildagliptin treatment $\quad(12.85 \pm 0.61$ vs. $11.54 \pm 0.48 \mathrm{mmol} / \mathrm{L}$ $[231 \pm 11$ vs. $208 \pm 9 \mathrm{mg} / \mathrm{dL}], P=0.04 ; 11.95 \pm 0.59$ vs. $9.33 \pm 0.64 \mathrm{mmol} / \mathrm{L}[215 \pm 11$ vs. $168 \pm 12 \mathrm{mg} / \mathrm{dL}]$, $P<0.01)$. However, there was no difference in IRI with the addition of vildagliptin, and the reduction in glucagon 1 and $2 \mathrm{~h}$ after the test meal showed only borderline significance $(85.9 \pm 5.2$ vs. $74.0 \pm 4.2 \mathrm{pg} / \mathrm{mL}, \quad P=0.05$; $75.2 \pm 5.2$ vs. $65.7 \pm 3.4 \mathrm{pg} / \mathrm{mL}, P=0.07)$.

Figure 2 shows changes in $\mathrm{AUC}_{0-2 \mathrm{~h}}$ for glucose, IRI, and glucagon. There was a significant reduction in glucose and glucagon $\mathrm{AUCs}_{0-2 \mathrm{~h}}$ with vildagliptin treatment compared with baseline $(22.75 \pm 1.03$ vs. $19.76 \pm 0.73 \mathrm{mmol} /$ L.h $\quad[410 \pm 19 \quad$ vs. $\quad 356 \pm 13 \mathrm{mg} / \mathrm{dL} \cdot \mathrm{h}], \quad P=0.01$; $161.4 \pm 9.5$ vs. $141.1 \pm 7.0 \mathrm{pg} / \mathrm{mL} \cdot \mathrm{h}, P=0.04$, respectively). However, IRI $\mathrm{AUC}_{0-2 \mathrm{~h}}$ did not differ between baseline and after addition of vildagliptin ( $45.6 \pm 7.1$ vs. $44.1 \pm 7.8 \mu \mathrm{U} / \mathrm{mL}, P=0.85$ ).

Table 2 shows the baseline comparison of blood glucose-related parameters between two groups based on median glucose $\Delta \mathrm{AUC}_{0-2 \mathrm{~h}}(1 \mathrm{st} \leq 3.56 \mathrm{mmol} / \mathrm{L}[64 \mathrm{mg} /$ dL] vs. 2 nd $\geq 3.61 \mathrm{mmol} / \mathrm{L}[65 \mathrm{mg} / \mathrm{dL}]$ ), and Table 3 shows the group comparison 6 months after the addition of vildagliptin. Fasting glucose and glucose $\mathrm{AUC}_{0-2 \mathrm{~h}}$ at baseline were significantly higher in the group showing greater improvement (2nd group glucose $\Delta \mathrm{AUC}_{0-2 \mathrm{~h}}$ $3.61 \mathrm{mmol} / \mathrm{L}[65 \mathrm{mg} / \mathrm{dL}]$, Table 2). At 6 months after the addition of vildagliptin, HOMA-IR and glucagon $\triangle \mathrm{AUCs}_{0-2 \mathrm{~h}}$ were significantly lower in this group, while IRI $\Delta \mathrm{AUC}_{0-2 \mathrm{~h}}$ showed no difference (Table 3). No adverse reactions (hypoglycemia, hepatic dysfunction, gastrointestinal dysfunction, renal dysfunction, cardiac failure, skin problems) due to vildagliptin were observed among these participants.

\section{Discussion}

Our results show that vildagliptin significantly improved blood glucose levels after MTT, and suppressed paradoxical glucagon elevation, but did not affect insulin release. These results support the use of MTT in clinical settings for evaluating interactions between blood glucose, IRI, and glucagon levels in response to treatment with DPP-4 inhibitors.

The improvement in glucose levels after the addition of a DPP-4 inhibitor in this study was similar to that in previous reports [6-9]. Treatment with DPP-4 inhibitors enhances insulin secretion in both the fasting and the postprandial phases due to inhibition of incretin cleavage. Pooled data from 327 patients in clinical trials in Japan showed that fasting insulin levels decreased $0.26 \pm 0.22 \mu \mathrm{U} / \mathrm{L} 12$ weeks after treatment with vildagliptin (50 mg bid) from $8.00 \pm 0.30 \mu \mathrm{U} / \mathrm{L}$ at baseline, but this difference was not statistically significant [10]. Insulin after MTT increases with single-dose administration of vildagliptin [8], but not with continuous vildagliptin administration [11, 12]. These findings may suggest that DPP-4 inhibitors do not increase insulin secretion aggressively, but maintain the blood concentration of incretins. In the study, four patients $(26.7 \%)$ were being treated with glimepiride and seven $(46.7 \%)$ with metformin, and these medications might affect the results. Despite these medications, our data showed that vildagliptin might also improve glycemic control without increasing insulin levels. Thus, DPP-4 inhibitors may be advantageous for improving glycemic control in that they do not cause excess insulin secretion.

The suppression of glucagon release may contribute to improved glycemic control in treatment with DPP-4 inhibitors. We found that glucagon elevation was significantly suppressed after adding vildagliptin, consistent with previous reports in Caucasian patients with T2DM [11, 13].
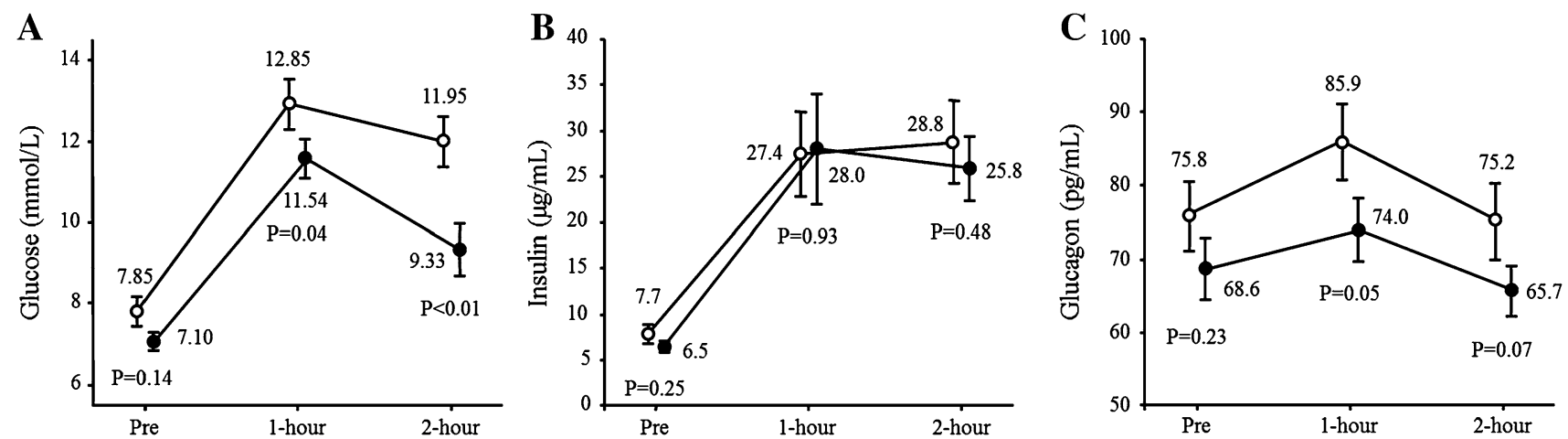

Fig. 1 Changes in (a) glucose concentration, (b) immune-reactive insulin, and (c) glucagon in the meal tolerance test before (open circles) and 6 months after the addition of vildagliptin (closed

circles). $P$ value indicates comparison between before and after the addition of vildagliptin. The values shown as circles are means and the bars represent the standard errors 

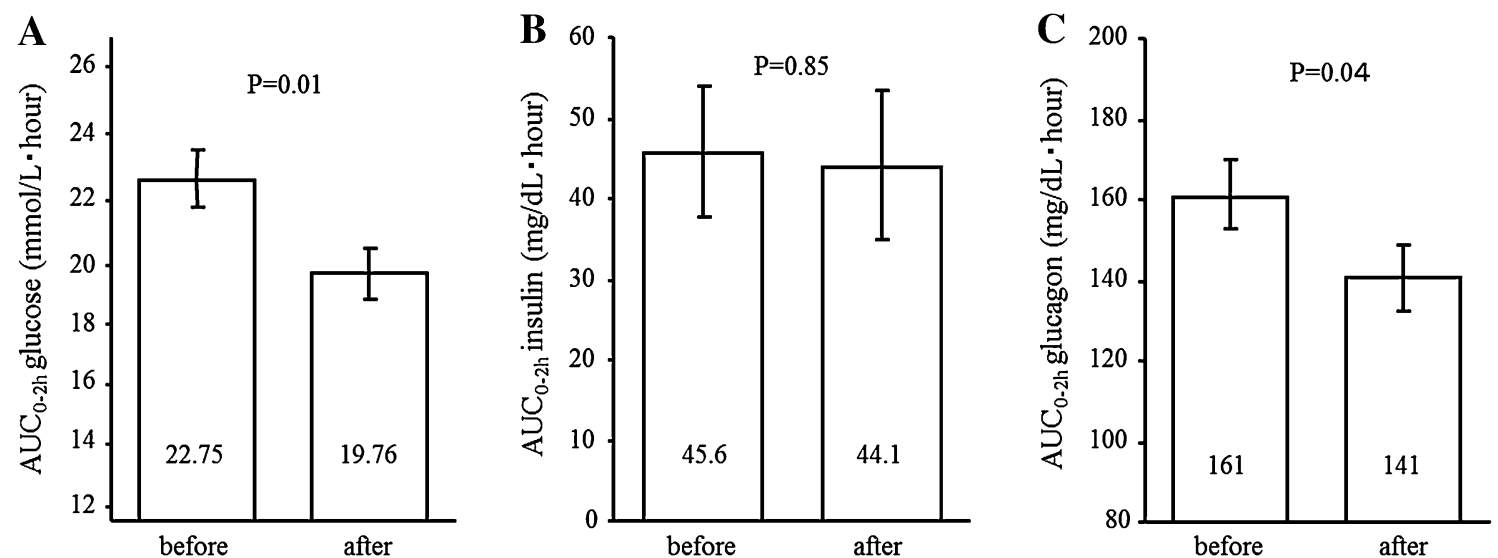

Fig. 2 Changes in the area under the curve $\left(\mathrm{AUC}_{0-2 \mathrm{~h}}\right)$ during the meal tolerance test for (a) glucose, (b) immune-reactive insulin, and

The values shown as circles are means and the bars represent the (c) glucagon before and 6 months after the addition of vildagliptin. standard errors

Table 2 Comparison of glucose-related parameters at baseline between glucose $\Delta \mathrm{AUC}_{0-2 \mathrm{~h}}$ groups after the addition of vildagliptin

\begin{tabular}{|c|c|c|c|}
\hline & 1 st $(n=8)(\leq 64 \mathrm{mg} / \mathrm{dL})^{\mathrm{a}}$ & $2 \mathrm{nd}(n=7)(>64 \mathrm{mg} / \mathrm{dL})^{\mathrm{a}}$ & $P$ value \\
\hline Male, $n(\%)$ & $5(62.5)$ & $5(71.4)$ & 0.71 \\
\hline Age (years) & $59.3 \pm 3.7$ & $51.3 \pm 4.1$ & 0.17 \\
\hline BMI $\left(\mathrm{kg} / \mathrm{m}^{2}\right)$ & $26.5 \pm 0.9$ & $27.5(1.3)$ & 0.53 \\
\hline \multicolumn{4}{|l|}{ Agents, $n(\%)$} \\
\hline Glimepiride & $2(25.0)$ & $2(28.6)$ & \\
\hline Metformin & $4(50.0)$ & $3(42.9)$ & \\
\hline $\mathrm{HbA}_{1 \mathrm{c}}(\%)$ & $7.43 \pm 0.18$ & $7.82 \pm 0.24$ & 0.21 \\
\hline HOMA-IR & $2.42 \pm 0.50$ & $3.06 \pm 0.70$ & 0.21 \\
\hline HOMA- $\beta$ & $46.3 \pm 8.9$ & $30.6 \pm 5.9$ & 0.18 \\
\hline Fasting glucose concentration $(\mathrm{mmol} / \mathrm{L})$ & $7.11 \pm 0.38$ & $8.69 \pm 0.45$ & 0.02 \\
\hline Fasting IRI $(\mu \mathrm{U} / \mathrm{mL})$ & $7.64 \pm 1.48$ & $7.83 \pm 1.65$ & 0.94 \\
\hline Fasting glucagon $(\mathrm{pg} / \mathrm{mL})$ & $72.3 \pm 7.1$ & $79.9 \pm 6.6$ & 0.45 \\
\hline $\mathrm{AUC}_{0-2 \mathrm{~h}}$ glucose $(\mathrm{mmol} / \mathrm{L} \cdot \mathrm{h})$ & $20.50 \pm 1.23$ & $25.32 \pm 1.09$ & 0.01 \\
\hline $\mathrm{AUC}_{0-2 \mathrm{~h}}$ IRI $(\mu \mathrm{U} / \mathrm{mL} \cdot \mathrm{h})$ & $54.3 \pm 11.5$ & $35.8 \pm 6.8$ & 0.21 \\
\hline $\mathrm{AUC}_{0-2 \mathrm{~h}}$ glucagon $(\mathrm{pg} / \mathrm{mL} \cdot \mathrm{h})$ & $149.8 \pm 10.7$ & $174.6 \pm 15.7$ & 0.21 \\
\hline
\end{tabular}

Data are presented as mean \pm standard error unless otherwise indicated

$A U C_{0-2 h}$ area under the curve $\left(\mathrm{AUC}_{0-2 \mathrm{~h}}\right)$ during the meal tolerance test, $B M I$ body mass index, $H b A_{1 c}$ glycated hemoglobin $\mathrm{A}_{1 \mathrm{c}}, H O M A-I R$ homeostasis model assessment-insulin resistance, HOMA- $\beta$ homeostasis model assessment-beta cell function, IRI immune-reactive insulin

${ }^{a}$ Groups based on median change in glucose $\mathrm{AUC}_{0-2 \mathrm{~h}}$ after the addition of vildagliptin

One possibility is that vildagliptin significantly inhibits glycogenesis in the liver at night by suppressing glucagon release [13].

In the study, we evaluate evaluated changes in glucose, insulin, and glucagon after MTT. A previous study to examine the pharmacodynamics, pharmacokinetics, and tolerability of sitagliptin using the oral glucose tolerance test (OGTT) reported that the near maximal glucose-lowering efficacy of sitagliptin after single oral doses was associated with inhibition of plasma DPP-4 activity of $80 \%$ or greater, corresponding to a plasma sitagliptin concentration of $100 \mathrm{~nm}$ or greater, and an augmentation of active glucagon-like peptide (GLP)-1 and glucose-dependent insulinotropic polypeptide (GIP) levels of twofold or higher after an OGTT [14]. An OGTT may be an appropriate method to evaluate efficacy of DPP-4 inhibitors. However, MTT can evaluate actual endogenous change in glucose, insulin and glucagon concentrations. It is possible that MTT may be appropriate to evaluate actual efficacy of DPP-4 inhibitors in actual setting.

Relating with limitations, we evaluated efficacy of only DPP-4 inhibitors in the study. An intervention study using a long-acting, human GLP-1 analog reported that taspoglutide at $20 \mathrm{mg}$ once weekly resulted in improvements 
Table 3 Comparison of glucose-related parameters at 6 months between glucose $\Delta \mathrm{AUC}_{0-2 \mathrm{~h}}$ groups after addition of vildagliptin

\begin{tabular}{|c|c|c|c|}
\hline & $1 \mathrm{st}(n=8)(\leq 64 \mathrm{mg} / \mathrm{dL})^{\mathrm{a}}$ & 2nd $(n=7)(>64 \mathrm{mg} / \mathrm{dL})^{\mathrm{a}}$ & $P$ value \\
\hline $\mathrm{HbA}_{1 \mathrm{c}}(\%)$ & $6.93 \pm 0.19^{*}$ & $6.58 \pm 0.12^{*}$ & 0.18 \\
\hline HOMA-IR & $2.39 \pm 0.23$ & $1.62 \pm 0.24$ & 0.04 \\
\hline HOMA- $\beta$ & $36.4 \pm 3.9$ & $39.7 \pm 9.0$ & 0.74 \\
\hline Fasting glucose concentration $(\mathrm{mmol} / \mathrm{L})$ & $7.53 \pm 0.8$ & $6.62 \pm 0.28^{*}$ & 0.04 \\
\hline Fasting IRI $(\mu \mathrm{U} / \mathrm{mL})$ & $7.14 \pm 0.66$ & $5.65 \pm 0.97$ & 0.22 \\
\hline Glucagon pre-meal test (pg/mL) & $72.6 \pm 6.3$ & $64.0 \pm 5.2$ & 0.32 \\
\hline $\mathrm{AUC}_{0-2 \mathrm{~h}}$ glucose $(\mathrm{mmol} / \mathrm{L} \cdot \mathrm{hr})$ & $20.30 \pm 0.99$ & $19.13 \pm 1.11^{*}$ & 0.45 \\
\hline $\mathrm{AUC}_{0-2 \mathrm{~h}} \mathrm{IRI}(\mu \mathrm{U} / \mathrm{mL} \cdot \mathrm{hr})$ & $55.8 \pm 12.5$ & $30.7 \pm 6.5$ & 0.11 \\
\hline AUC $_{0-2 \mathrm{~h}}$ glucagon $(\mathrm{pg} / \mathrm{mL} \cdot \mathrm{hr})$ & $147.9 \pm 11.0$ & $133.4 \pm 8.3^{*}$ & 0.32 \\
\hline$\Delta \mathrm{AUC}_{0-2 \mathrm{~h}}$ glucose $(\mathrm{mmol} / \mathrm{L} \cdot \mathrm{hr})$ & $-0.20 \pm 1.15$ & $-6.18 \pm 0.85$ & $<0.01$ \\
\hline$\Delta \mathrm{AUC}_{0-2 \mathrm{~h}} \mathrm{IRI}(\mu \mathrm{U} / \mathrm{mL} \cdot \mathrm{hr})$ & $1.54 \pm 13.5$ & $-5.1 \pm 9.5$ & 0.70 \\
\hline$\Delta \mathrm{AUC}_{0-2 \mathrm{~h}}$ glucagon $(\mathrm{pg} / \mathrm{mL} \cdot \mathrm{hr})$ & $-1.9 \pm 11.1$ & $-41.2 \pm 13.5^{*}$ & 0.04 \\
\hline
\end{tabular}

$A U C_{O-2 h}$ area under the curve during the meal tolerance test, $H b A_{l c}$ glycated hemoglobin $\mathrm{A}_{1 \mathrm{c}}, H O M A-I R$ homeostasis model assessment-insulin resistance, HOMA- $\beta$ homeostasis model assessment-beta cell function, IRI immune-reactive insulin, $\triangle A U C_{0-2 h}$ difference in $\mathrm{AUC}_{0-2 \mathrm{~h}}$ before and after addition of vildagliptin

* $P<0.05$ vs. before the addition of vildagliptin

${ }^{\text {a }}$ Groups based on change in glucose $\mathrm{AUC}_{0-2 \mathrm{~h}}$ after the addition of vildagliptin

from baseline in oral glucose insulin sensitivity (OGIS), $\beta$ cell glucose sensitivity, glucagon/glucose and insulin/glucagon ratios, and the disposition index during the MTT [15]. Analysis with GLP-1 treatment is required in further studies.

\section{Limitation}

This study has several limitations worth noting. First, there may have been selection bias given the small sample size and the fact that patients were from one medical institution specializing in diabetes treatment. In addition, there was no control group. A large-scale multicenter controlled study will be needed to better compare our data with those from other medical settings. Second, important factors such as health behavior, incretin measurements, and other hormones (norepinephrine, growth hormone, and cortisol) were not evaluated. Such factors should also be evaluated in future studies. Finally, 6 months is a relatively short follow-up period. As a next step, cohort studies with long follow-up periods should be conducted to assess long-term outcomes, including glycemic control. Third, the concentrations of glucose and insulin at 30 min were not measured and the insulinogenic index could not be calculated in the study $[16,17]$. Further study is required with these measurements to examine early-phase insulin and glucagon secretion.

Acknowledgments The authors thank the staff of Okamoto Medical Clinic for their excellent help in data collection. This study was funded by a 2012 Grant-in-Aid for Scientific Research (C) (No.
24590816). The authors take full responsibility for the content of the manuscript, participated in all stages of manuscript development, and approved the final manuscript for publication.

Conflict of interest All authors declare no conflict of interest.

Compliance with ethics guidelines Study protocol was reviewed and approved by The Council of Okamoto Medical Clinic. All procedures followed were in accordance with ethical standards of responsible committee on human experimentation (institutional and national) and with the Helsinki Declaration of 1975, as revised in 2000 and 2008. Informed consent was obtained from all patients in the study. The Council of Okamoto Medical Clinic reviewed and approved the research protocol.

Author Contributions A.O. designed and conducted the study and collected data. A.O. and H.Y. analyzed the data and wrote the manuscript. H.S. supervised the results.

Open Access This article is distributed under the terms of the Creative Commons Attribution Noncommercial License which permits any noncommercial use, distribution, and reproduction in any medium, provided the original author(s) and the source are credited.

\section{References}

1. D'Alessio D. The role of dysregulated glucagon secretion in type 2 diabetes. Diabetes Obes Metab. 2011;13(Suppl 1):126-32.

2. Cryer PE. Minireview: glucagon in the pathogenesis of hypoglycemia and hyperglycemia in diabetes. Endocrinology. 2012;153:1039-48.

3. Nauck MA. Unraveling the science of incretin biology. Am J Med. 2009;122(6 Suppl):S3-10.

4. Drucker DJ. The biology of incretin hormones. Cell Metab. 2006;3:153-65. 
5. Matthews DR, Hosker JP, Rudenski AS, et al. Homeostasis model assessment: insulin resistance and beta-cell function from fasting plasma glucose and insulin concentrations in man. Diabetologia. 1985;28:412-9.

6. Kikuchi M, Abe N, Kato M, et al. Vildagliptin dose-dependently improves glycemic control in Japanese patients with type 2 diabetes mellitus. Diabetes Res Clin Pract. 2009;83:233-40.

7. Iwamoto Y, Kashiwagi A, Yamada N, et al. Efficacy and safety of vildagliptin and voglibose in Japanese patients with type 2 diabetes: a 12-week, randomized, double-blind, active-controlled study. Diabetes Obes Metab. 2010;12:700-8.

8. Rosenstock J, Foley JE, Rendell M, et al. Effects of the dipeptidyl peptidase-IV inhibitor vildagliptin on incretin hormones, islet function, and postprandial glycemia in subjects with impaired glucose tolerance. Diabetes Care. 2008;31:30-5.

9. He YL, Ligueros-Saylan M, Sunkara G, Vildagliptin, et al. Vildagliptin, a novel dipeptidyl peptidase IV inhibitor, has no pharmacokinetic interactions with the antihypertensive agents amlodipine, valsartan, and ramipril in healthy subjects. J Clin Pharmacol. 2008;48:85-95.

10. Kadowaki T, Chujo M, Sagara R, et al. Clinical efficacy of monotherapy with vildagliptin in patients with type 2 diabetes: pooled data analysis from clinical trials in development phase in Japan. J New Rem Clin. 2011;60:217-30 (in Japanese).

11. Mari A, Scherbaum WA, Nilsson PM, et al. Characterization of the influence of vildagliptin on model-assessed-cell function in patients with type 2 diabetes and mild hyperglycemia. J Clin Endocrinol Metab. 2008;93:103-9.

12. Pratley RE, Schweizer A, Rosenstock J, et al. Robust improvements in fasting and prandial measures of beta-cell function with vildagliptin in drug-naïve patients: analysis of pooled vildagliptin monotherapy database. Diabetes Obes Metab. 2008;10:931-8.

13. Balas B, Baig MR, Watson C, et al. The dipeptidyl peptidase IV inhibitor vildagliptin suppresses endogenous glucose production and enhances islet function after single-dose administration in type 2 diabetic patients. J Clin Endocrinol Metab. 2007;92:1249-55.

14. Herman GA, Bergman A, Stevens C, et al. Effect of single oral doses of sitagliptin, a dipeptidyl peptidase- 4 inhibitor, on incretin and plasma glucose levels after an oral glucose tolerance test in patients with type 2 diabetes. J Clin Endocrinol Metab. 2006;91:4612-9.

15. Gastaldelli A, Nauck MA, Balena R. Eight weeks of treatment with long-acting GLP-1 analog taspoglutide improves postprandial insulin secretion and sensitivity in metformin-treated patients with type 2 diabetes. Metabolism. 2013;62:1330-9.

16. Nonaka K, Kakikawa T, Sato A, et al. Efficacy and safety of sitagliptin monotherapy in Japanese patients with type 2 diabetes. Diabetes Res Clin Pract. 2008;79:291-8.

17. Ohkura T, Fujioka Y, Sumi K, et al. Sitagliptin improves the impaired acute insulin response during a meal tolerance test in japanese patients with type 2 diabetes mellitus. Diabetes Ther. 2014;5:285-97. 